NASA Technical Memorandum 101981

\title{
Starting Characteristics of Direct Current Motors Powered by Solar Cells
}

\author{
(NASA-TH-1019E1) STARTINE CEALCTEEISTICS \\ CF DIEECT CUREELT MCTCES FCFELIL EY SOLAE \\ $N 89-194 \leq 3$ \\ CELLS (AASA) $20 \mathrm{~F}$ \\ CSCL C9A

\section{G3/33 $\begin{array}{ll}\text { Unclas } \\ 0197273\end{array}$}

S. Singer

University of Colorado

Colorado Springs, Colorado

and

J. Appelbaum

Lewis Research Center

Cleveland, Ohio

March 1989 
STARTING CHARACTERISTICS OF DIRECT CURRENT MOTORS

POWERED BY SOLAR CELLS

S. Singer*

University of Colorado

Colorado Springs, CO 80933

and

J. Appelbaum**

National Aeronautics and Space Administration

Lewis Research Center

Cleveland, Ohio 44135

\begin{abstract}
Direct current motors are used in photovoltaic systems. Important characteristics of electric motors are the starting to rated current and torque ratios. These ratios are dictated by the size of the solar cell array and are different for the various dc motor types. The paper deals with the calculation of the starting to rated current ratio and starting to rated torque ratio of the permanent magnet, separately, series and shunt excited motors when powered by solar cells for two cases: with and without a maximum-power-point-tracker (MPPT) included in the system. Comparing these two cases, one gets a torque magnification of about 3 for the permanent magnet motor and about 7 for other motor types. The calculation of the torques may assist the PV system designer to determine whether or not to include an MPPT in the system.
\end{abstract}

*On sabbatical leave from Tel Aviv University.

** This work was done while the author held a National Research Council (NASA Lewis Research Center) Research Associateship, on sabbatical leave from Tel Aviv University. 


\section{INTROOUCTION}

Direct current ( $d c$ ) motors are used in photovoltaic (PV) drive systems (Refs. 1 to 6), for example, in cooling application where the motors drive reciprocating vapor compressors, and in water-pumping systems for irrigation or water supply where motors drive positive displacement or centrifugal pumps. In a direct coupled (with no battery storage) PV system, the solar cell array is directly connected to the motor-load couple. These systems are relatively simple and inexpensive to operate. A direct coupled system may include a maximum power point tracker (MPPT) to improve its performance whenever it is needed (Ref. 7). In PV drive systems, such as in water pumping systems, the static head may be relatively high causing the motor-load to stay in standstill position until sufficient torque is developed at relatively high insolation. By including an MPPT in the system, the starting torque may increase significantly at lower insolation levels resulting in desired system performance.

The starting to rated current ratio and the starting to rated torque ratio are two important characteristics of a dc motor. For various dc motor types these ratios are different, and since these motors may be used in different applications in PV systems, the starting current and torque ratios are characteristics for the PV system designer to calculate. The paper deals with the calculation of the starting current and torque ratios for the permanent magnet; separately, series and shunt excited dc motor for two cases: (1) when an MPPT is not included in the system and (2) when an MPPT is included in the system. Current and torque magnification factors are then defined by comparing these two cases for various types of the dc motors. The analysis of this study may assist the PV system designer to determine whether or not to include an MPPT in the design for a specific motor type. The motor 
torque is related to the motor current, while a high motor starting torque is usually a desirable characteristic, a high motor starting current is undesirable. It is to the advantage to obtain a high magnification of the motor starting torque accompanied with an allowable magnification of the motor starting current in a system including an MPPT.

The calculation of the motor starting currents and torques of the various motor types was made with some assumptions and approximations. Nevertheless, they are not too far off from real values and, therefore, can be used for comparison between the different motors in systems both with and without MPPT's. A main assumption is the linear dependence of the magnetic flux on the field current. Another assumption reflects the field and armature reactances. The currents and torques would result in somewhat lower values without these assumptions.

\section{MOTOR EQUATIONS}

The circuit diagram of permanent magnet, series, shunt and separately excited motors are shown in Fig. $1(a)$ to $(d)$, respectively. The motor voltage and torque equations are:

$$
\begin{aligned}
V_{m} & =E+I_{a} R \\
E & =k_{e} \phi n \\
T & =k_{T} \phi I_{a}
\end{aligned}
$$

where

$\begin{array}{ll}V_{m} & \text { the motor applied voltage, } V \\ E & \text { the motor-electro-motive force, e.m.f., } V \\ I_{a} & \text { the motor armature current, } A \\ R & \text { the motor armature circuit resistance, } \Omega \\ \phi & \text { the motor flux, Wb } \\ n & \text { the motor shaft speed, rpm }\end{array}$


T the motor electromagnetic torque, $\mathrm{N} \cdot \mathrm{m}$

$k_{e}, k_{T}$ the motor voltage and torque constants, respectively

Assuming a linear dependence of the magnetic flux on the field current (a linear motor model) one can write the following relations:

(a) for the permanent magnetic motor;

$$
\phi=C_{1} \quad \text { and } \quad T=C_{2} I_{a}
$$

(b) for the series motor;

$$
\phi=C_{3} I_{2}, \quad T=C_{4} I_{a}^{2}, \quad \text { and } \quad R=R_{2}+R_{S}
$$

(c) for the shunt motor;

$$
\begin{gathered}
\phi=C_{5} I_{f} \quad \text { and } T=C_{6} I_{a} I_{f} \\
I_{m}=I_{a}+I_{f} \quad \text { and } I_{f}=\frac{V_{m}}{R_{s h}} \\
T=C_{7} I_{a} I_{f}
\end{gathered}
$$

(d) for the separately excited motor;

$$
\phi=C_{8} I_{f}, \quad T=C_{g} I_{a} I_{f}, \quad \text { and } \quad I_{f}=\frac{V_{f}}{R_{s h}}
$$

where

Im the motor terminal current

If the shunt and separately excited motor field current

$R_{S}$ the series motor field resistance

$R_{\text {sh }}$ the shunt and separately excited motor field resistance

$\mathrm{C}_{1}-\mathrm{C}_{9}$ constants

For the permanent magnet and series motors we write:

$$
I_{m}=I_{a}
$$

By direct coupling the motor to the solar cells we have:

$$
V_{m}=V \quad \text { and } \quad I_{m}=I
$$


where $V$ and I are the array voltage and current, respectively. For the purpose of comparing the different motor types, it is assumed that the rated armature voltage drop (including the voltage drop on the brushes) for all motor types is 10 percent of the rated motor terminal voltage. A good system design corresponds to rated motor operation $V_{n}$, In close to the maximum power point $V_{M}$, IM of the solar cell array. The insolation level for rated motor operation is taken to be about 0.8 Sun for the appropriate array. The ratio of the short circuit current $I_{S C}$ to the maximum power-current $I_{M}$ of the solar cell array is about 1.2. This ratio; the armature voltage drop percentage; and the motor rated operation is used in the analysis for all motor types, i.e.,

$$
I_{M}=I_{n}, \quad V_{M}=V_{n}, \quad \frac{I_{n} R}{V_{n}}=0.1 \quad \text { and } \quad \frac{I_{S C}}{I_{M}}=1.2
$$

The system's operating point $I_{M}, V_{M}$ is determined by the intersection of the I-V characteristics of the solar cell array with the I-V characteristic of the motor (Eq. (1)) as shown in Fig. 2. The slope of the motor characteristic is $\theta=\tan ^{-1} 1 / R$, and since the resistance of the armature circuit is low, the slope $\theta$ is large. At the instant of motor starting $n=0$, therefore $E=0$. The motor characteristic is thus represented by a straight line with a slope of $\tan ^{-1} 1 / R$ passing through the origin as shown in Fig. 2. The starting current is approximately the short circuit current of the array, i.e.,

$$
I_{\text {St }} \cong I_{\text {SC }}
$$

MOTOR STARTING CURRENT AND TORQUE RATIOS WITHOUT AN MPPT IN THE SYSTEM

Permanent Magnet Motor

The motor starting current is:

$$
I_{S t}=I_{\alpha} \cong I_{S C}
$$


The starting current ratio is:

$$
\frac{I_{s t}}{I_{n}}=\frac{I_{s c}}{I_{M}}
$$

i.e., this ratio (Eq. (12)) is 1.2 .

The motor starting torque ratio is given by Eqs. (4) and (15), i.e.,

$$
\frac{T_{s t}}{T_{n}}=\frac{I_{s C}}{I_{M}}
$$

where $T_{s}$ and $T_{n}$ are the starting and rated torques, respectively. This ratio is 1.2 .

\section{Series Excited Motor}

The motor starting current and starting current ratio are:

$$
I_{s t}=I_{a} \cong I_{s C} \quad \text { and } \quad \frac{I_{s t}}{I_{n}}=\frac{I_{s C}}{I_{M}}
$$

The starting current ratio (Eq. (12)) is 1.2 .

The motor starting torque ratio is given by Eqs. (5) and (16):

$$
\frac{T_{s t}}{T_{n}}=\left(\frac{I_{s C}}{I_{M}}\right)^{2}
$$

This ratio (Eq. (12)) is 1.44 .

\section{Shunt Excited Motor}

We shall first calculate the rated armature current and torque. At the maximum power point, the rated armature current according to Eq. (7) is:

$$
I_{a}=I_{M}-I_{f}=I_{M}-\frac{V_{M}}{R_{s h}}
$$

and the rated motor torque according to Eq. (8) is:

$$
T_{n}=C_{7}\left(I_{M}-\frac{V_{M}}{R_{s h}}\right) \frac{V_{M}}{R_{s h}}
$$


At starting $(E=0)$, the motor is represented by two resistors connected in parallel: the armature $R_{a}$ and field $R_{s h}$ resistors, i.e., $R_{a} \| R_{s h}$. The motor terminal current is $I_{m} \cong I_{S C}$, therefore, the armature current at starting is:

$$
I_{a, s t} \cong I_{s c} \frac{R_{a} \| R_{s h}}{R_{a}}
$$

Since $R_{a} \| R_{S h} \approx R_{2}$, the starting to rated current ratio is about $I_{S C} / I_{M}$, i.e., 1.2 .

The field current at starting is:

$$
I_{f, s t} \cong I_{s C} \frac{R_{d} \| R_{s h}}{R_{s h}}
$$

The shunt motor starting torque, according to Eq. (8) becomes:

$$
T_{s t}=C_{7} I_{s c}^{2} \frac{\left(R_{2} \| R_{s h}\right)^{2}}{R_{a} R_{s h}}
$$

and the motor starting torque ratio (Eqs. (20) and (23)) is:

$$
\frac{T_{s t}}{T_{n}}=\frac{I_{s c}^{2} \frac{\left(R_{d} \| R_{s h}\right)^{2}}{R_{a} R_{s h}}}{\left(I_{M}-\frac{V_{M}}{R_{s h}}\right) \frac{V_{M}}{R_{s h}}}
$$

Equation (24) can be approximated by $I_{M} \gg I_{f}$ and $R_{s h} \gg R_{a}$ resulting in:

$$
\frac{T_{s t}}{T_{n}} \cong\left(\frac{I_{s c}}{I_{M}}\right)^{2} \frac{I_{M} R_{a}}{V_{M}}
$$

This ratio, according to Eq. (12) is 0.14 , i.e., the starting torque ratio of the shunt motor is very low and is usually not sufficient to overcome the starting torque of the mechanism. This low value is attributed by the low field current at starting. 
Separately Excited Motor

A shunt excited motor may be wired as a separate excited motor by connecting the field and the armature circuits to two separate sources. In this arrangement, we have, at starting, two separate resistive loads: the field resistive load, and the armature circuit resistive load which are connected to two separate solar cell sources. It has been shown (Ref. 8) that the total output power of loads connected to separate sources is higher than the total output power of the same loads when connected to a common source, for load lines operating only in the current range of the $I-V$ characteristics of the solar cells (Fig. 2). The higher output power results also in higher starting torque as is shown in the following analysis.

A solar cell array is usuaily composed of a number of strings connected in parallel. The array can then be split into a larger array for the armature circuit, and a smaller array for the field circuit according to the power requirement of each circuit, as shown in Fig. 3 . If ' $a$ ' is the number of strings of the whole array for the shunt motor, ' $a-b$ ' would be the number of strings for the armature-array, and ' $b$ ' would be the number of strings for the field-array. The rated field current and voltage correspond to the maximum power point of the field array, i.e., If,M and $V_{M}$, respectively. Since the original unsplit array operated at its maximum power point, $I_{M}$ and $V_{M}$, the field current is:

$$
I_{f, M}=I_{M}\left(\frac{b}{a}\right)
$$

or with Eq. (7)

$$
\left(\frac{b}{a}\right)=\frac{V_{M}}{I_{M} R_{s h}}
$$

The armature current at starting is:

$$
I_{a, s t} \cong I_{s c}\left(\frac{a-b}{a}\right)
$$


The motor starting current is $I_{a, s t}+I_{f, M} \approx I_{S C}$, and the starting current ratio is $I_{S C} / I_{M}=1.2$. The starting torque becomes:

$$
T_{s t}=C_{7} I_{s c}\left(\frac{a-b}{a}\right) I_{M}\left(\frac{b}{a}\right)
$$

Dividing Eq. (29) by Eq. (20) and with Eq. (27) we get the starting torque ratio of the separate excited motor:

$$
\frac{T_{s t}}{T_{n}}=\frac{I_{s C}}{I_{M}}
$$

i.e., splitting the solar cell array into an armature and field arrays and connecting separately the armature and the field circuits to the above arrays, the starting to rated torque ratio of the shunt motor is considerably increased, and is the same as for the permanent magnet motor, i.e., $I_{S C} / I_{m}=1.2$.

MOTOR STARTING CURRENT AND TORQUE RATIOS WITH AN MPPT IN THE SYSTEM By matching the solar cell array to the motor by means of a "maximum power point tracker" (MPPT), the motor operation can be improved. The MPPT consists of a power processing circuit, as Buck, Buck/Boost, or Boost (Ref. 9) circuits, controlled by a signal circuit unit which drives the power processing circuit such that the solar cell array operates at its maximum power point. The power processing circuit of the MPPT can be modeled by a controlled time-variable-transformer (TVT) (Ref. 10) in which the transformation ratio $k$ is changed continuously, corresponding to variation in the load operating point. A system consisting of a solar cell array, an MPPT and a de motor is shown in Fig. 4. The motor is represented by the e.m.f. $E$ and the armature circuit resistance $R$; the TVT is assumed to be loss free, therefore all of the array power is delivered to the motor load. The input/output equations of the TVT are: 


$$
\left[\begin{array}{l}
V \\
I
\end{array}\right]=\left[\begin{array}{cc}
k & 0 \\
0 & k^{-1}
\end{array}\right]\left[\begin{array}{c}
V_{m} \\
I_{m}
\end{array}\right]
$$

where $k$ is the transformation ratio.

The desired matching is achieved by controlling $k$ such that the array operates at its maximum power-voltage and current, i.e.,

$$
\left[\begin{array}{l}
V \\
I
\end{array}\right] \Rightarrow\left[\begin{array}{l}
V_{M} \\
I_{M}
\end{array}\right]
$$

The motor voltage equation is:

$$
V_{m}=E+I_{m} R
$$

Using Eqs. (31) to (33) and solving for $k$ we get:

$$
k=\left[\frac{E}{2 V_{M}}+\sqrt{\left(\frac{E}{2 V_{M}}\right)^{2}+\frac{I_{M}{ }^{R}}{V_{M}}}\right]^{-1}
$$

The motor voltage $V_{m}$ and current $I_{m}$ are related to $V_{M}$ and $I_{M}$ of the array by:

$$
V_{m}=\frac{V_{M}}{k} \quad \text { and } \quad I_{m}=k I_{M}
$$

At motor starting $E=0$ and $E q$. (34) reduces to:

$$
k_{s t}=\left(\frac{V_{M}}{I_{M} R}\right)^{1 / 2}=\left(\frac{P_{M}}{I_{M}^{2} R}\right)^{1 / 2}
$$

Using Eqs. (35) and (36), the motor starting current is:

$$
I_{m, s t}=\left(\frac{P_{M}}{R}\right)^{1 / 2}=\left(\frac{V_{M} I_{M}}{R}\right)^{1 / 2}
$$

In the previous section we have calculated the starting current and torque ratios of the different de motors when an MPPT was not included in the system. The starting current and torque are increased when an MPTT is 
included in the system, the amount of which depends on the motor type. The increase or the magnification of the starting current and torque will now be calculated. We define current and torque magnification factors $m_{I}$ and $m_{T}$ by the ratio of the starting current and torque with an MPPT to the starting current and torque without an MPPT, respectively:

$$
m_{I}=\frac{I_{s t} \text { with MPPT }}{I_{s t} \text { without MPPT }}, \quad m_{T}=\frac{T_{s t} \text { with MPPT }}{T_{s t} \text { without MPPT }}
$$

Permanent Magnet Motor

The motor starting current without and with an MPPT is given by Eqs. (14) and (37), respectively;

$$
m_{I}=\frac{\left(\frac{V_{M} I_{M}}{R}\right)^{1 / 2}}{I_{S C}}=\left(\frac{I_{M}}{I_{S C}}\right)\left(\frac{V_{M}}{I_{M} R}\right)^{1 / 2}=\left(\frac{I_{M}}{I_{S C}}\right)\left(\frac{V_{n}}{I_{n} R}\right)^{1 / 2}
$$

Using Eq. (12), the current magnification is $m_{I}=2.64$. Since the motor torque is directly proportional to the armature current, the torque magnification is also $m_{T}=2.64$.

\section{Series Excited Motor}

The starting current magnification (Eqs. (12), (17), and (37) is:

$$
m_{I}=\frac{\left(\frac{V_{M} I_{M}}{R}\right)^{1 / 2}}{I_{S C}}=\left(\frac{I_{M}}{I_{S C}}\right)\left(\frac{V_{n}}{I_{n} R}\right)^{1 / 2}=2.64
$$

and since for a series motor the torque is proportional to the square of the armature current we have:

$$
m_{T}=\frac{\left(\frac{V_{M} I_{M}}{R}\right)}{I_{S C}^{2}}=\left(\frac{I_{M}}{I_{S C}}\right)^{2}\left(\frac{V_{n}}{I_{n} R}\right)=6.94
$$




\section{Shunt Excited Motor}

At starting, the equivalent motor resistance is $R_{a} \| R_{s h}$. The motor starting current is given by Eq. (37), i.e.,

$$
I_{m, s t}=\left(\frac{P_{M}}{R_{a} \| R_{s h}}\right)^{1 / 2}
$$

The armature current at starting is:

$$
I_{a, s t}=I_{m, s t} \frac{R_{a} \| R_{s h}}{R_{a}}\left(\frac{P_{M}}{R_{a} \| R_{s h}}\right)^{1 / 2} \frac{R_{a} \| R_{s h}}{R_{a}}
$$

and the field current at starting is:

$$
I_{f, s t}=\left(\frac{P_{M}}{R_{a} \| R_{s h}}\right)^{1 / 2} \frac{R_{d} \| R_{s h}}{R_{f}}
$$

The starting current magnification (Eq. (12) and $R_{a} \ll R_{s h}$ ) is

$$
m_{I}=\frac{\left(\frac{P_{M}}{R_{d} \| R_{s h}}\right)^{1 / 2}}{I_{s c}} \approx\left(\frac{I_{M}}{I_{s c}}\right)\left(\frac{V_{n}}{I_{n} R_{d}}\right)^{1 / 2}=2.64
$$

The motor torque is proportional to the armature and field current, and using Eqs. (12), (21), (22), (43), and (44), the torque magnification factor is:

$$
m_{T}=\frac{P_{M}}{I_{S C}^{2}\left(R_{d} \| R_{s h}\right)} \cong\left(\frac{I_{M}}{I_{s c}}\right)^{2} \frac{V_{n}}{I_{n} R_{d}}=6.94
$$

i.e., the same as for the series motor.

Separately Excited Motor

The shunt motor can operate as a separately excited motor by connecting the armature and field circuits to separate voltages as shown in Fig. 5, where the field current is directly connected to the array that operates at $V_{M}$ and $I_{M}$, and the armature is powered through the MPPT. The field current is: 


$$
I_{f, M}=\frac{V_{M}}{R_{s h}}
$$

The power delivered to the armature circuit is:

$$
P_{2}=P_{M}-\frac{V_{M}^{2}}{R_{s h}}
$$

and the armature starting current according to Eq. (37) is:

$$
I_{a, s t}=\left[\left(P_{M}-V_{M}^{2} / R_{s h}\right) / R_{a}\right]^{1 / 2}
$$

The starting current and torque magnification of the separately excited motor can be calculated for two cases depending whether or not the solar cell array can be split into two arrays: one for the armature circuit and the other for the field circuit. It should be noted that not always is it worthwhile cor possible) to split the array. Comparing the magnifications to a system without an MPPT where the array can be split, the starting current magnification (Eqs. (47), (49)), and $I_{a, s t}+I_{f}, M \cong I_{S C}$ is:

$$
m_{I}=\left[\left(\frac{P_{M}-v_{M}^{2} / R_{s h}}{R_{a}}\right)^{1 / 2}+\frac{V_{M}}{R_{s h}}\right] / I_{s c}
$$

Since $I_{d} \gg I_{f}, m_{I} \cong\left(I_{M} / I_{s c}\right)\left(V_{n} / I_{n} R_{d}\right)^{1 / 2}=2.64$.

The starting torque magnification is obtained by Eqs. (27), (29), (47), and (49),

$$
m_{T}=\frac{V_{M} / R_{S h}\left[\left(P_{M}-V_{M}^{2} / R_{S h}\right) / R_{a}\right]^{1 / 2}}{I_{S C}\left(\frac{a-b}{a}\right) I_{M}\left(\frac{b}{a}\right)}
$$

Using the approximation $b / a \ll 1, P_{M}-V_{M}^{2} / R_{s h} \equiv P_{M}$ and $E q .(12)$, we have: 


$$
\mathrm{m}_{T} \cong\left(\frac{I_{M}}{I_{s c}}\right)^{2} \frac{v_{n}}{I_{n} R_{a}}=6.94
$$

For the case where the solar cell array is not split, the separately excited motor operates as a shunt excited motor in the system without an MPPT. In this case, the starting current magnification is given by Eq. (50) since $R_{a} \| R_{s h} \approx R_{a}$. The torque magnification factor is obtained by Eqs. (21), (22), (47), and (49):

$$
m_{T}=\frac{V_{M} / R_{s h}\left[\left(P_{M}-V_{M}^{2} / R_{s h}\right) / R_{a}\right]^{1 / 2}}{I_{s c}^{2}\left(R_{d} \| R_{s h}\right)^{2} / R_{a} R_{s h}}
$$

With the approximation of $R_{a} \| R_{s h} \approx R_{a}, P_{M}-V_{M}^{2} / R_{s h} \approx P_{M}$, and $E q .(12)$, we have

$$
m_{T}=\left(\frac{V_{n}}{I_{n} R_{a}}\right)^{3 / 2}\left(\frac{I_{M}}{I_{s c}}\right)^{2}=21.96
$$

It should be noted that the starting torque magnification is very high since the starting torque of the shunt motor without an MPPT, is very low. It is worthwhile mentioning that in all cases of current and torque magnifications, these factors are a function of the motor parameters $V_{n}, I_{n}, R$, and the solar cell array parameters $I_{M}$ and $I_{S C}$.

\section{CONCLUSIONS}

The starting current and torque ratios of the permanent magnet; separately, series, and shunt excited dc motors powered by solar cell arrays were calculated for systems with and without a maximum-power-point-tracker. Starting current $m_{I}$ and starting torque $m_{T}$ magnification factors were defined by the ratio of the starting current and starting torque of the motor with an MPPT to the corresponding values without an MPPT. The results are summarized in Table 1. The salient result of the study is the high 
magnification of the starting torque of the $d c$ motors in systems including MPPT's. It also shows that whereas the starting current magnification of all motor types is about the same, 2.64 (depending on the approximation), the starting torque magnification is about the same, 6.94, for the series, shunt, and one of possible connection of the separately excited motors; 1ower, 2.64, for the permanent magnet motor; and very high, 21.96, for the other possible connection of the separately excited motor. The starting torque of the shunt motor remains low even when an MMPT is included in the system. The starting to rated torque value of the permanent magnet motor is in the allowable range, but the starting torque ratio of the series and separately excited motor may be too high for the drive system. In these cases the MPPT may be controlled to operate off the maximum power point to meet the desired torque. The torque magnifications were obtained for linear modeling of the motors. If nonlinearity is considered, the above values would somewhat be lower. The analysis presented in this paper may assist the PV system designer to determine the starting currents and torques for the different motor types, and the magnification of these values when MPPT's are included in the system. 


\section{REFERENCES}

1. Sir William Halcrow and Partners, "Small-Scale Solar-Powered Pumping System: The Technology, Its Economic and Advancement,: UNDP Project GLO/80/003, Executed by The World Bank, June 1983.

2. Y.R. Hsido, B.A. Blevins, "Direct Coupling of Photovoltaic Power Source to Water Pumping System," Solar Energy, Vol. 32, No. 4, pp. 489-498, 1984.

3. W.R. Anis, R.P. Meters, R.J. Van Overstraeten, "Coupling of a Volumetric Pump to a Photovoltaic Array," Solar Cells, Vol. 14, pp. 27-42, 1985.

4. D.L. Pulfrey, P.R.B. Ward, W.G. Dunford, "A Photovoltaic-Powered System for Medium Head Pumping," 18th IEEE PVSC, pp. 1637-1642, Las Vegas, Oct. 21-25, 1985.

5. J. Appelbaum, "Starting and Steady-State Characteristics of D.C. Motors Powered by Solar Cell Generators," IEEE Trans. On Energy Conversion, Vol. EC-1, No. 1, pp. 17-25, 1986.

6. J.P. Dunlop, "Analysis and Design Optimization of Photovoltaic Water/Pumping Systems," 20th IEEE PVSC, Las Vegas, Sept. 26-30, 1988.

7. S. Singer, A. Braunstein, "The Maximum Power Transfer from a Nonlinear Energy Source to an Arbitrary Load," IEE Proc. Vol. 134, No. 4, pp. $281-287,1987$.

8. J. Appelbaum, "The Operation of Loads Powered by Separate Sources or by a Common Source of Solar Cells," IEEE 1989 Winter Power Meeting, paper No. 89 WM002-7EC, Jan. 29-Feb. 3, 1989, New York.

9. R.D. Middlebrook, "Small Signal Modeling of Pulse Width Modulated Switched Mode Power Converters," Proc. IEEE, Vol. 76, No. 4, pp. 343-354, 1988.

10. S. Singer, "Canonical Approach to Energy Processing Network Synthesis," IEEE Trans. On Circuits and Systems, Vol. CAS-33, No. 8, pp. 767-774, 1986. 


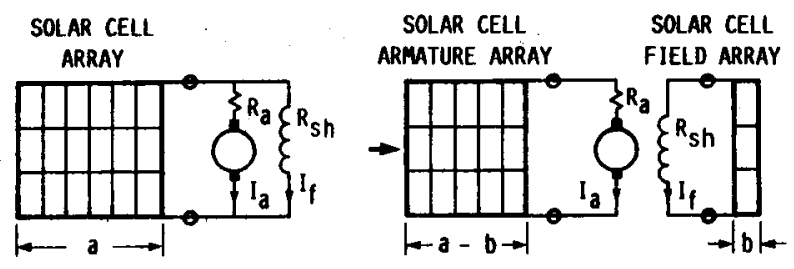

FIGURE 3. - ARRAY SPLIT INTO ARMATURE AMD FIELD ARRAYS.

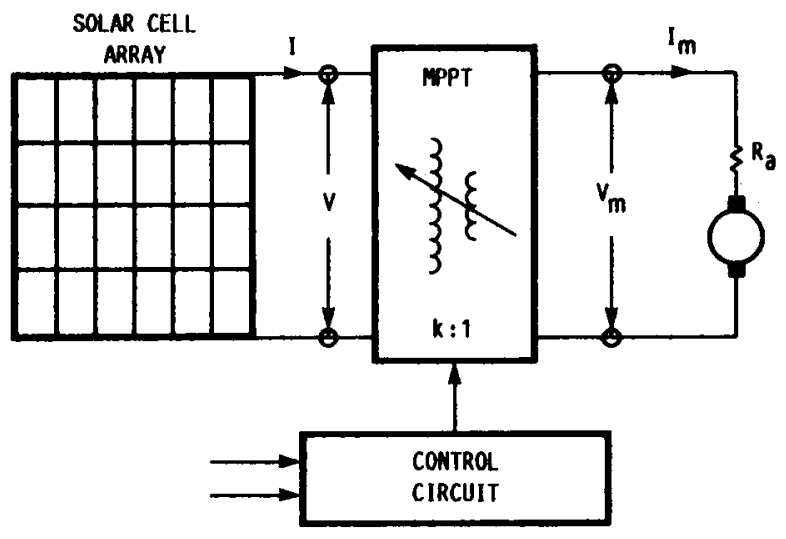

FIGURE 4. - SOLAR CELL SYSTEM WITH AN MPPT.

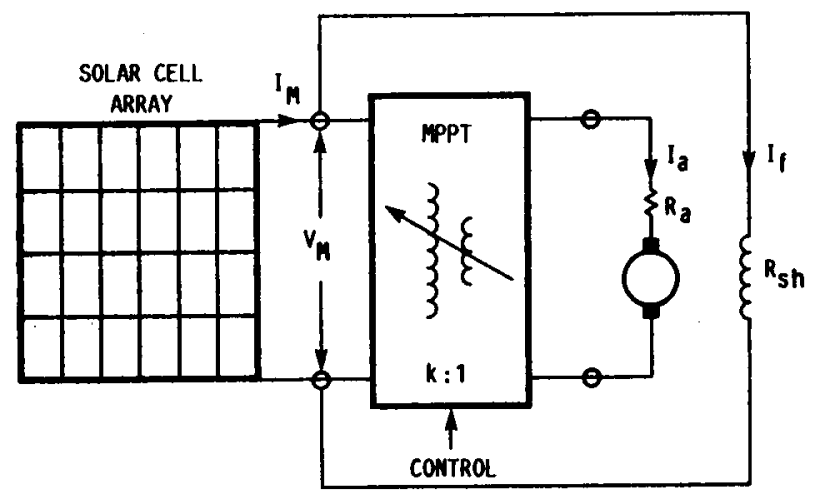

FIGURE 5. - SEPARATELY EXCITED MOTOR CONMECTED TO A SOLAR CELL ARRAY WITH AN MPPT. 


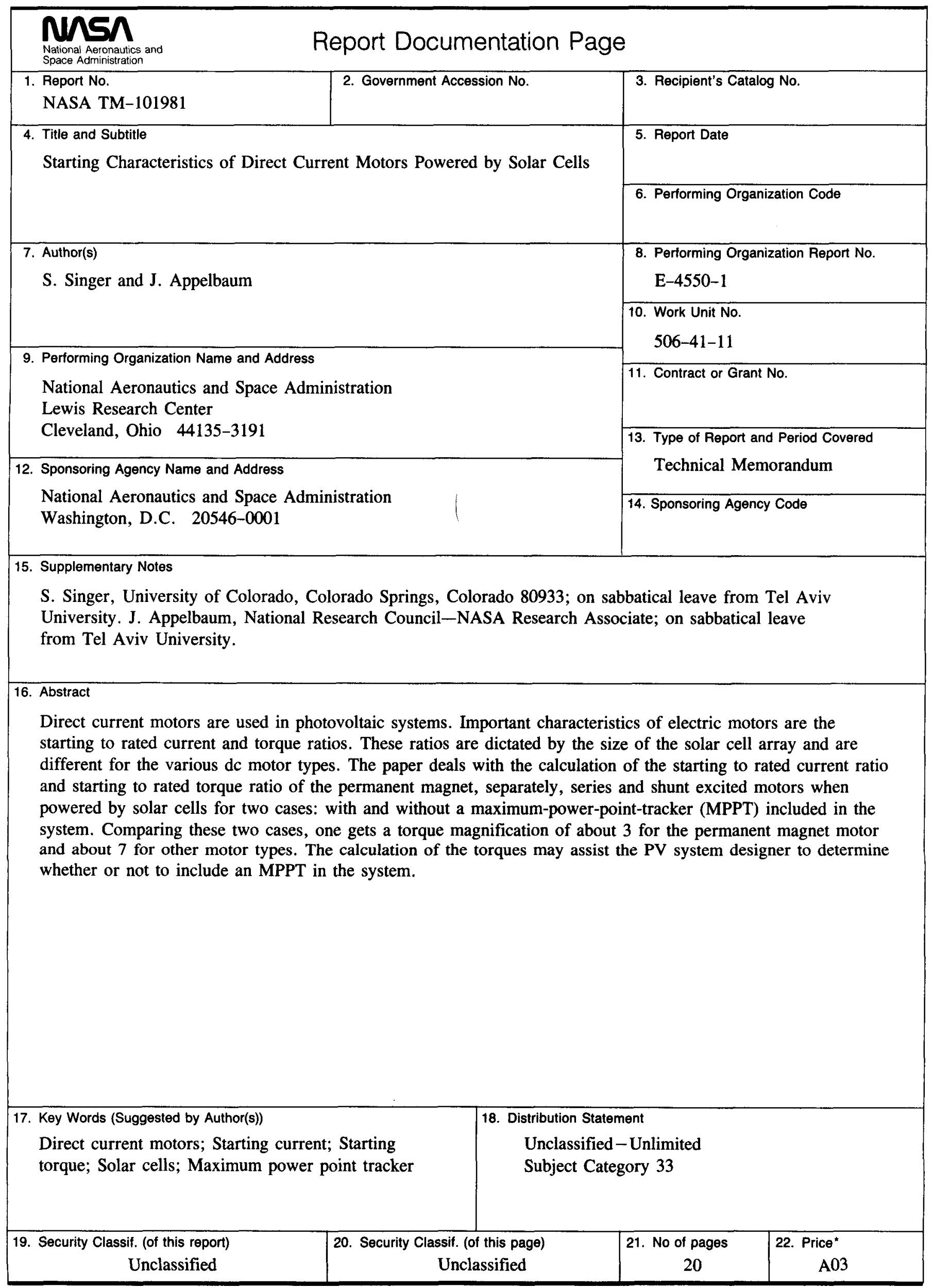

